\title{
High Arctic biocrusts: characterization of the exopolysaccharidic matrix
}

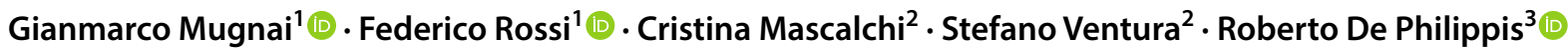

Received: 17 June 2019 / Revised: 9 September 2020 / Accepted: 10 September 2020 / Published online: 23 September 2020

(c) The Author(s) 2020

\begin{abstract}
Biocrusts can be found in a wide array of habitats, where they provide important ecosystem services. These microbial associations are particularly important in High Arctic environments, where biocrust colonize the newly exposed barren soil after glacier retreat and significantly contribute to soil stabilization and nutrient cycling. Starting from incipient, structurally simple biolayers, they develop in complexity, increasing from the glacier terminus. Starting from a simple community structure, mainly constituted by cyanobacteria, heterotrophic bacteria and fungi immersed in a self-secreted extracellular polymeric matrix (cyanobacterial crusts), they later may recruit mosses and lichens (moss crusts and lichen crusts, respectively). The extracellular polymeric matrix protects the biocrust community from abiotic constraints, notably drought and freezing stress, from external physical harming factors, and from predation. The physicochemical characteristics of the extracellular matrix are related to several of its properties, such as its soil-stabilizing effect and water retention. We analysed the chemical (monosaccharidic composition) and macromolecular (molecular weight distribution) properties of the extracellular polymeric matrix of biocrusts with different morphologies collected in northwestern Spitsbergen, Norway. The uronic acid content and molecular weight (MW) distribution of the extracellular polysaccharidic matrices (EPMs) appeared in accordance with the developmental stages of the biocrusts. The MW distribution also showed significant differences between the samples, possibly reflecting differences in microbial enzymatic activities leading to the degradation of high-MW polymers into smaller compounds. The MW distribution profiles presented some important differences, reflecting differences in environmental conditions and, probably, the seasonal variance in microbial community composition that is known to characterize the environment examined in the present study.
\end{abstract}

Keywords Biocrusts $\cdot$ Arctic environment $\cdot$ Extracellular polysaccharidic matrix (EPM) $\cdot$ Extracellular polymeric substances (EPS)

Gianmarco Mugnai and Federico Rossi equally contributed to this manuscript as first authors.

Electronic supplementary material The online version of this article (https://doi.org/10.1007/s00300-020-02746-8) contains supplementary material, which is available to authorized users.

Roberto De Philippis

roberto.dephilippis@unifi.it

1 Department of Food, Environmental and Nutritional Sciences (DeFENS), University of Milan, Via Mangiagalli 25, 20133 Milano, Italy

2 Research Institute on Terrestrial Ecosystems (IRET), CNR, Via Madonna del Piano 10, 50019 Sesto fiorentino (FI), Italy

3 Department of Agriculture, Food, Environment and Forestry (DAGRI), University of Florence, Via Maragliano 77, 50144 Firenze, Italy

\section{Introduction}

In arid and semiarid environments, microorganisms can be found in association with biocrusts colonizing the topsoil. Biocrusts are complex associations of cyanobacteria, heterotrophic bacteria, microalgae, fungi and lichens in varying proportions that have a primary ecological role (Yoshitake et al. 2010; Williams et al. 2017). They are common in High Arctic tundra, where they develop on newly exposed soil after deglaciation and exert beneficial effects on vegetation establishment and succession (Breen and Lévesque 2008). Biocrusts contribute to soil water retention, soil stabilization and nutrient cycling in thin and undeveloped soil owing to their photosynthetic and nitrogen-fixation potentials (Yoshitake et al. 2010). They originate from pioneer organisms, recognized mainly as cyanobacteria (Pushkareva et al. 
2019), that form incipient biolayers on barren soils, favouring later colonization by other microbial species and more complex organisms (Belnap and Lange 2001). This results in biocrusts with different gradients of development starting in the glacier foreland, from an incipient cyanobacteria-dominated stages to more mature consortia that also incorporate mosses, lichens and small plants (Breen and Lévesque 2008; Yoshitake et al. 2010).

Beginning with the first incipient stages of development, biocrust organisms secrete a three-dimensional extracellular polymeric matrix (EPM) that embeds soil sediments and bacterial filaments, keeping them firmly in place (Mugnai et al. 2018a). The EPM derives from the accumulation of extracellular polymeric substances (EPSs), mainly secreted by cyanobacteria, constituted by different classes of biological molecules, mainly polysaccharides, proteins, lipids and nucleic acids (Al-Thani 2015; Rossi et al. 2018). Cyanobacteria are abundant in biocrust communities in locations around Ny-Ålesund (Jung et al. 2018). Some surveys showed that Arctic biocrusts are inhabited by cyanobacterial communities mainly represented by the orders Synechococcales, Nostocales and Oscillatoriales (Pushkareva et al. 2015), including several filamentous genera such as Microcoleus spp. and Leptolyngbya spp. These genera have a high ability to stabilize the substrate by the concerted action of the trichomes and the copious amount of EPSs that they produce (Chamizo et al. 2018; Mugnai et al. 2018b; Chock et al. 2019). In addition, EPSs protect cells from several types of stresses, notably drought and cryoturbation (Tamaru et al. 2005; Varin et al. 2012), binding water molecules and affecting water permanence at the topsoil (Colica et al. 2014). EPSs are composed of polymers having different molecular weights (MWs) as a result of combined microbial synthetic and degradative processes, the latter capable of transforming high-MW EPSs into smaller polymers or oligomers. These are easily utilizable as primary $\mathrm{C}$ sources by the heterotrophic microbial community (Mager and Thomas 2011; Chen et al. 2014; Rossi et al. 2018). Easily assimilable carbon sources, such as glucose and galactose, have profound impacts on community structure while stimulating the decomposition rates of old organic matter in the permafrost subsoil (Fierer et al. 2003; Wild et al. 2014). Microbial enzymatic activity leading to polymer degradation is affected by several parameters, including community composition and interactions (facilitation/ competition) between microbial species (Miralles et al. 2012; Li et al. 2013). Some studies strongly suggest correlations between EPS physicochemical characteristics and the capability to aggregate loose soil and, in general, to contribute positively to biocrust establishment. Recent investigations conducted in sand microcosms attempted to clarify the relationships between the monosaccharidic composition of EPSs, their MW distribution and the development and physical stability of biocrusts (Mugnai et al. 2018a, b; Mugnai et al. 2020). For example, some EPS properties, such as a hydrophobic or a hydrophilic nature, are determined by the presence of specific types of sugar constituents and functional groups (Pereira et al. 2009; Colica et al. 2015). However, these types of correlative studies are still hampered by the limited information currently available on the physicochemical characteristics of biocrust EPMs, so it is currently difficult to extrapolate general concepts. A limited number of biocrust typologies from a limited number of habitats were analysed for EPM features. Particularly, analyses were performed on induced biocrusts at different stages of development from semiarid soils in Inner Mongolia, China, and natural biocrusts from North American deserts (Rossi et al. 2012a, b; Colica et al. 2014, 2015; Chen et al. 2014). However, to the best our knowledge, there are no data concerning the characteristics of the EPM of biocrusts from High Arctic environments.

In this work, we investigated, for the first time, the chemical and macromolecular features of the EPM of biocrusts with different morphological traits collected on the northwestern coast of Spitsbergen, Svalbard Archipelago. We hypothesized that the morphological differences of the biocrusts also reflected differences in the physicochemical features of the EPM. Additionally, we compared the detected EPM characteristics with those of biocrusts from hot arid and semiarid environments, with the aim of understanding whether different environmental and climatic conditions significantly affect EPM features.

\section{Materials and methods}

\section{Study sites and sample collection}

The study area is located in the surroundings of the research town of Ny-Ålesund on the northwest coast of Spitsbergen Island $\left(78.9^{\circ} \mathrm{N}, 11.9^{\circ} \mathrm{E}\right)$. The environment is classified as Arctic tundra and characterized either as a lime-demanding, moderate snowbed environment colonized by Saxifraga oppositifolia and Cetraria delisei or as an acidophilous moderated snowbed environment. In addition, wetter sites are dominated by mosses and Deschampsia alpina (Krzyszowska 1989). The Svalbard archipelago is characterized by relatively mild climatic conditions. The mean temperature of Ny-Ålesund is $8{ }^{\circ} \mathrm{C}$ in summer and $-14{ }^{\circ} \mathrm{C}$ in winter, although temperatures as low as $-35^{\circ} \mathrm{C}$ were also registered. The average annual precipitation is $471 \mathrm{~mm}$, falling prevalently (70\%) between October and May, mainly as snow (Mann et al. 1986; Williams et al. 2017). The soil parameters are detailed in Online Resource 1. 


\section{Sampling and biocrust morphology}

Sampling took place from 27th to 31st August 2010 in several locations around Ny-Ålesund (Fig. 1). The sampling strategy was to collect samples with as much morphological diversity as possible and that were representative of the main morphological types of biocrusts surrounding the research station. Sampling sites were significantly far apart from one another (Table 1) to avoid any possible reciprocal interference between them. Additionally, biocrust were collected in
Fig. 1 Maps of Svalbard Archipelago, Norway, and of the sampling sites. Location of Svalbard (a), Topographic map (b) and indication of the sampling sites around the research town of Ny-Ålesund (c). Maps are used courtesy of the Norwegian Polar Institute
Table 1 Sample denomination, and sampling location (name, latitude/longitude, altitude and distance between sampling sites)

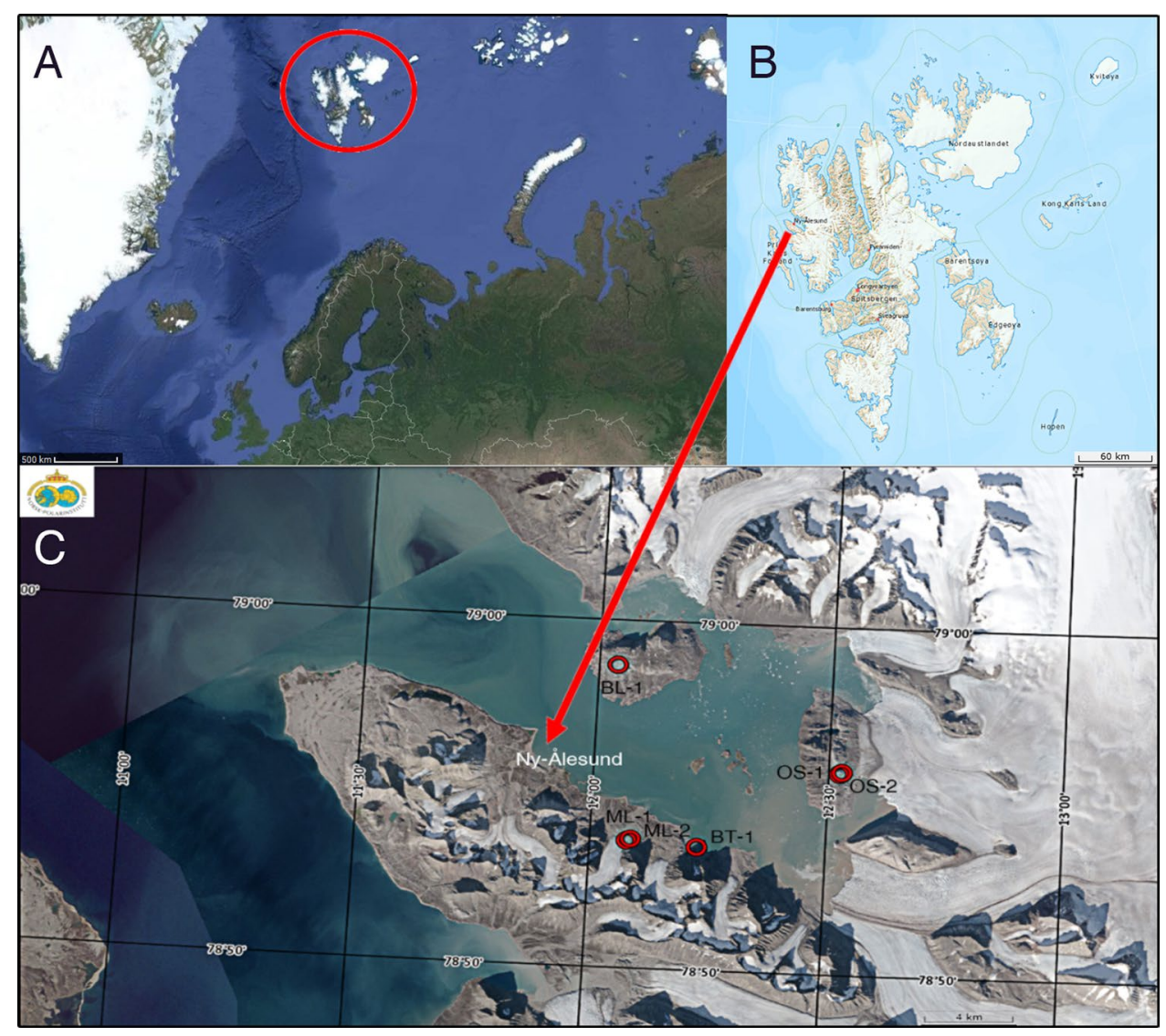

\begin{tabular}{lllll}
\hline Sample & Sampling location & Latitude/longitude & $\begin{array}{l}\text { Altitude } \\
\text { (metres } \\
\text { above sea } \\
\text { level) }\end{array}$ & $\begin{array}{l}\text { Distances from the } \\
\text { nearest sampling sites } \\
\text { (kilometres) }\end{array}$ \\
& & & 60 & 0.23 (ML-2) \\
ML-1 & Midtre Lovénbreen & $\begin{array}{l}78^{\circ} 53^{\prime} 39.2^{\prime \prime} \mathrm{N} \\
12^{\circ} 04^{\prime} 47.8^{\prime \prime} \mathrm{E}\end{array}$ & & 9.44 (BL-1) \\
ML-2 & Midtre Lovénbreen & $7^{\circ} 53^{\prime} 42.2^{\prime \prime} \mathrm{N}$ & 58 & 9.44 (BL-1) \\
& & $12^{\circ} 05^{\prime} 15.7^{\prime \prime} \mathrm{E}$ & & 10.1 (OS-1) \\
BL-1 & Blomstrandhalvøya, Kongsfjorden & $78^{\circ} 58^{\prime} 41.1^{\prime \prime} \mathrm{N}$ & 247 & 11.7 (OS-1) \\
& & $12^{\circ} 02^{\prime} 22.6^{\prime \prime} \mathrm{E}$ & & 10.5 (BT-1) \\
OS-1 & Ossian Sars, Kongsfjorden & $78^{\circ} 55^{\prime} 46.2^{\prime \prime} \mathrm{N}$ & 121 & 10.3 (ML-1) \\
& & $12^{\circ} 31^{\prime} 24.2^{\prime \prime} \mathrm{E}$ & & 0.17 (OS-2) \\
& & & 7.57 (BT-1) \\
OS-2 & Ossian Sars, Kongsfjorden & $78^{\circ} 55^{\prime} 50.0^{\prime \prime} \mathrm{N}$ & 46 & 10.3 (ML-2) \\
& & $12^{\circ} 31^{\prime} 44.5^{\prime \prime} \mathrm{E}$ & & 11.8 (BL-1) \\
& & & 10.5 (ML-1) \\
BT-1 & Botnbreen, Kongsfjorden & $78^{\circ} 53^{\prime} 32.0^{\prime \prime} \mathrm{N}$ & 20 & 3.22 (ML-1) \\
& & $12^{\circ} 13^{\prime} 44.6^{\prime \prime} \mathrm{E}$ & & 3.06 (ML-2) \\
& & & 7.76 (OS-2)
\end{tabular}


spots that were clear of plants and shrubs. Samples were collected by pushing the open side of sterile plastic Petri dishes (92 mm diameter $\times 16 \mathrm{~mm}$ depth) into the soil, subsequently sealing the Petri dishes closed using parafilm, and transporting the dishes to the laboratory.

The morphological traits of the biocrust samples are shown in Fig. 2.

\section{Chlorophyll a content}

Chlorophyll $a$ was extracted and quantified according to the method reported in Castle et al. (2011). Briefly, dry crust samples were homogenized, weighed, extracted with ethanol at $80^{\circ} \mathrm{C}$, and then cooled at room temperature for $5 \mathrm{~min}$. The absorbance of the supernatants was measured at $665 \mathrm{~nm}$ and $750 \mathrm{~nm}$ with a UV-Visible spectrophotometer (Cary, Varian Inc.). The value of the absorbance at $750 \mathrm{~nm}$ was subtracted from that at $665 \mathrm{~nm}$ to account for the residual scattering of the ethanol solution. The corrected absorbance $\left(\mathrm{A}_{665}^{\mathrm{c}}\right)$ was then plotted with the equation:

$\left[11.9035 \times\left(\mathrm{A}_{665}^{\mathrm{c}}\right) \times \mathrm{V}\right]\left(\mathrm{g} \mathrm{soil}^{-1}\right) \times \mathrm{L}^{-1}$

where $\mathrm{V}$ is the volume of the analysed extract (expressed in litres) and $\mathrm{L}$ is the path length (expressed in $\mathrm{cm}$ ).

\section{Extraction and quantification of the extracellular polymeric substances}

EPSs were quantified as total extracellular carbohydrates (TECs) and high molecular weight extracellular carbohydrates (HMWECs), the fraction of TECs having a molecular weight (MW) larger than $100 \mathrm{kDa}$. Dry biocrust samples were homogenized, weighed and treated with $\mathrm{Na}_{2}$ EDTA at $0.1 \mathrm{M}$ for $15 \mathrm{~min}$ according to Underwood et al. (1995). Afterwards, samples were centrifuged at $3600 \times g$ at $8{ }^{\circ} \mathrm{C}$ for $20 \mathrm{~min}$, and a fraction of each TEC-containing
Fig. 2 Surface morphology of biocrusts collected on the northwest coast of Spitsbergen Island, Svalbard Archipelago, Norway. Sample ML-1: lichen crust. Sample ML-2: brown crust with a roughened surface morphology. Sample OS-1: black crust sparsely colonized by lichens. Sample OS-2: thick brown crust sparsely colonized by mosses. Sample BL-1: discontinuous moss crust developed on a rocky substrate. Sample BT-1: smooth crust with scattered lichens and mosses. Dimensions of the ruler: $20 \mathrm{~cm}$
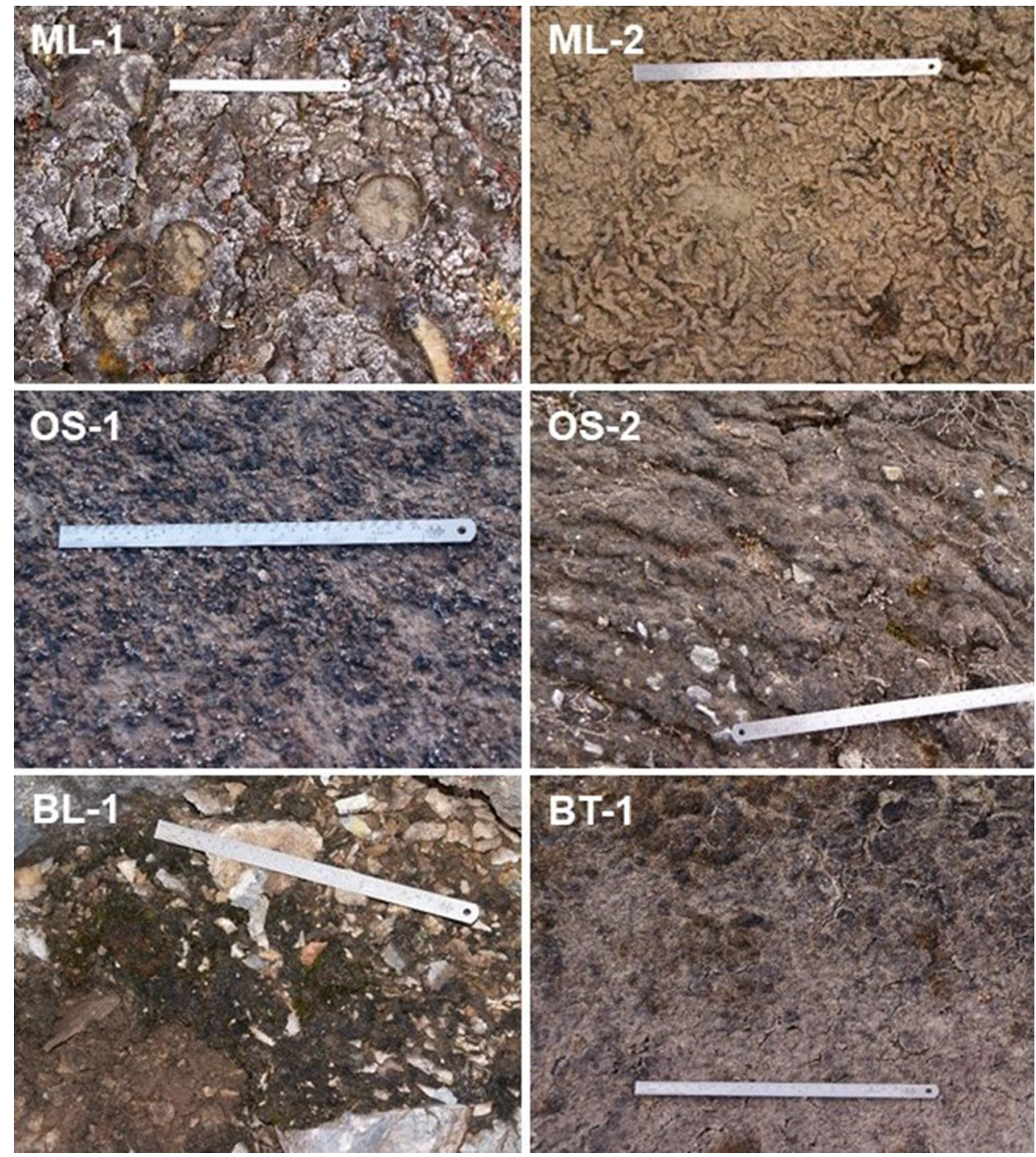
supernatant was stored frozen for further analysis. To recover the HMWECs, the remaining supernatants were precipitated in cold ethanol (70\% final concentration) at $4{ }^{\circ} \mathrm{C}$ for $16 \mathrm{~h}$, a treatment previously reported to be capable of precipitating EPSs with a MW higher than $100 \mathrm{kDa}$ (Brouwer and Stal 2001). HMWEC-containing precipitates were resuspended in deionized water and stored frozen for further analysis. TEC and HMWEC contents were finally determined using a phenol-sulfuric acid assay (Dubois et al. 1956) and expressed as mg per $\mathrm{g}$ soil.

\section{Analysis of the monosaccharidic composition of the extracellular polysaccharides}

TEC-containing supernatants were confined in dialysis tubes (14,000 Da MW cut-off, Medicell International, London) and dialyzed against distilled water for $24 \mathrm{~h}$, with two changes of water to remove the $\mathrm{Na}_{2}$ EDTA that could interfere with the analytical procedures. Furthermore, TECs were dried in a rotary evaporator and then treated with $2 \mathrm{~N}$ trifluoroacetic acid (TFA) at $120^{\circ} \mathrm{C}$ for $2 \mathrm{~h}$ before finally cooling on ice. Before instrumental analysis, samples were ultrafiltered using centrifugal filters (Ultra-4 Amicon, Billerica, MA) at $8200 \times g$ for $20 \mathrm{~min}$ and then washed three times with deionized water in a rotary evaporator to remove the residual TFA. The monosaccharidic composition was analysed with a Dionex ICS-2500 ion-exchange chromatograph equipped with an ED-50 detector with a gold-working electrode and a Carbopac PA1 column with a length of $250 \mathrm{~mm}$ and internal diameter of $4.6 \mathrm{~mm}$ (Dionex, Sunnyvale, $\mathrm{CA}$ ). The eluents were deionized water (A), $0.185 \mathrm{M} \mathrm{NaOH}$ (B) and $0.488 \mathrm{M}$ sodium acetate $(\mathrm{C})$. Chromatographic conditions were in accordance with those described in Chen et al. (2014). In the first stage (1st to 7th minute), the eluent combination was $84 \% \mathrm{~A}, 15 \% \mathrm{~B}$, and $1 \% \mathrm{C}$; in the second stage (7th to 16th minute), the eluent combination was $0 \% \mathrm{~A}, 50 \%$ $\mathrm{B}$ and $50 \% \mathrm{C}$; and in the final stage (16th to 30th minute), the eluent combination matched that of the first stage. The flow rate was constant at $1 \mathrm{~mL} \mathrm{~min}^{-1}$. Sugars in the extracts were identified and quantified according to reference standards. The composition of monosaccharides of the EPSs was expressed as a molar percent, i.e. as moles of the specific sugar divided by the total moles of the sugars present in the EPSs $\times 100$ (De Philippis and Vincenzini 1998).

\section{Molecular weight distribution profile of the extracellular polysaccharidic matrix}

Dry TECs were dissolved in deionized water and clarified by ultracentrifugation at $13,000 \times g$ to remove coarse particulates. Samples were analysed using a Varian Prostar HPLC chromatograph equipped with two size-exclusion (SEC) columns, Polysep-GFC-P 6000 and 4000 (Phenomenex
Inc., USA) connected in series, and a refractive index detector. Samples were analysed with runs of $65 \mathrm{~min}$ at a flow rate of $0.4 \mathrm{~mL} \mathrm{~min}{ }^{-1}$, according to the method of Colica et al. (2015). Apparent MWs of the samples were identified according to standards of dextran at different average MWs (40,000-5000 kDa; $2000 \mathrm{kDa} ; 485 \mathrm{kDa} ; 72.6 \mathrm{kDa}$; $0.34 \mathrm{kDa}$ ) purchased from Sigma Aldrich. The standards were first incubated at $40{ }^{\circ} \mathrm{C}$ to dryness by evaporation and then solubilized in distilled water before injection into the chromatograph.

\section{Statistical analysis}

Biocrust samples were collected in triplicate (biological replicates, $N=3$ ). Each measurement was performed three times on each biological replicate (technical replicates, $n=3$ ). The significance of the data was evaluated using one-way analysis of variance (ANOVA) at 95\% significance. To correlate parameters, linear regression analyses were performed, and $r^{2}$ and $p$ values are reported for each case. Statistical analysis was performed using GraphPad Prism version 5.00 (GraphPad software, USA). Monosaccharidic composition and MW distribution data were organized in matrices and analysed by principal component analysis (PCA) via the PAST 3 software package (https://folk.uio.no/ohammer/past/).

\section{Results}

\section{Biocrust classification and chlorophyll a content}

According to the thresholds reported in Lan et al. (2013), sample BL-1 is classifiable as a moss crust, since mosses cover at least $75 \%$ of the crust surface, while sample BT- 1 is classifiable as a semi-moss crust, being colonized by mosses over $20 \%$ of the crust surface. Sample ML-1 is technically a lichen crust, as lichens cover at least $20 \%$ of the crust surface, and no moss colonization is present. Samples ML-2, OS- 1 and OS-2 are classifiable as cyanobacterial crusts.

The highest contents of chlorophyll $a$ were found in samples BL-1, BT-1 and OS-2. The highest values were found in sample BL-1, followed by BT-1 and then OS-2. The remaining samples (ML-1, ML-2 and OS-1) showed lower and nonsignificantly different contents (Fig. 3).

\section{Extracellular carbohydrate quantification}

The TEC and HMWEC contents of biocrusts are reported in Fig. 4. The average TEC content ranged between 1.45 and $3.48 \mathrm{mg} \mathrm{g}^{-1}$ dry soil. Samples ML-1, BL-1 and OS-2 contained larger TEC amounts. Samples BL-1 and OS-2 also showed the highest contents of HMWECs (TECs with a MW $>100 \mathrm{kDa}$ ) among the samples. The percentages of 


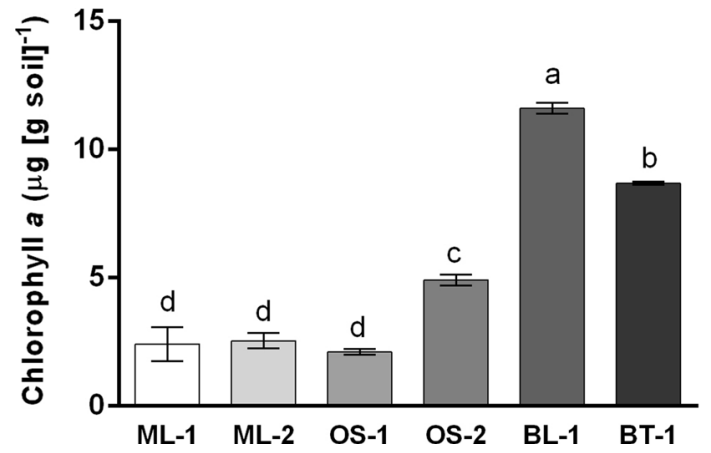

Fig. 3 Chlorophyll $a$ content of biocrust samples. Results (expressed as $\mu \mathrm{g}$ per $\mathrm{g}$ dry soil) are the means of three replicates $(N=3)$. Different lowercase letters indicate a significant difference $(p<0.05)$

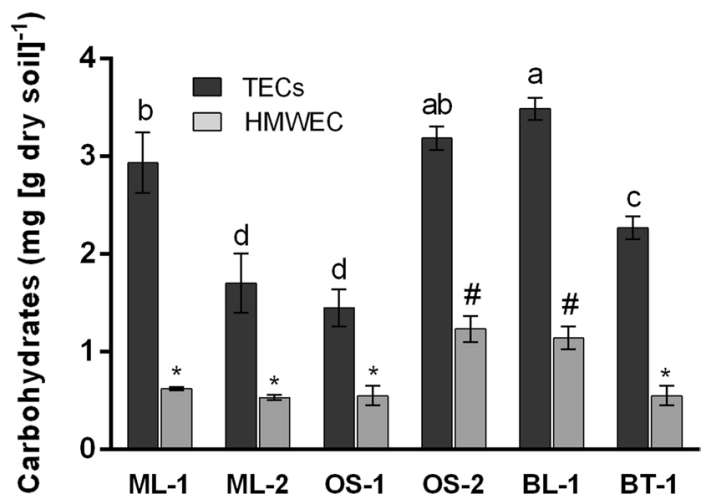

Fig. 4 Extracellular carbohydrate contents of biocrusts. Carbohydrate contents (expressed as mg per g dry soil) are subdivided into total extracellular carbohydrates (TECs, dark bars) and high molecular weight extracellular carbohydrates (HMWECs, light bars) in the biocrust samples. Results are the means of three experimental replicates $(N=3)$ Different lowercase letters indicate a significant difference in TEC contents $(p<0.05)$. Different symbols $(\#, *)$ indicate a significant difference between HMWEC contents $(p<0.05)$

TECs accounted for by HMWECs ranged from 21\% (sample ML-1) to $39 \%$ (sample OS-2). No statistically significant correlations were found between extracellular carbohydrates (TECs or HMWECs) and chlorophyll $a$ content $\left(r^{2}=0.105\right.$, $p=0.530$ and $r^{2}=0.115, p=0.511$, respectively).

\section{Monosaccharidic composition of the extracellular polymeric substances}

The polysaccharidic fraction of the EPM was complex in terms of monosaccharidic composition and up to 13 different types of monosaccharides were identified (Table 2). Glucose (Glc), mannose (Man) and galacturonic acid (GalA) were the most representative constituents. Cumulative amounts of Glc and Man ranged from 27.52\% (sample ML-1) to $70.02 \%$ (sample BT-1) of the total sugar moles. Glc alone was highest in sample BT-1 and lowest in sample ML-1. GalA was present in the largest amount $(34.02 \%)$ in sample ML-1. The total uronic acid content (i.e. glucuronic acid (GlcA) and GalA cumulative content) was highest in the EPMs of sample ML-1 (44.78\%) and sample BL-1 (38.02\%) (Table 2).

PCA (Online Resource 2 and 4) showed that Glc and GalA had the highest loadings in the first two principal components, explaining $79 \%$ and $16.8 \%$ of the total variance, respectively.

\section{Molecular weight distribution of extracellular polymeric substances}

The EPMs extracted from the biocrusts showed high polydispersity, but with significant differences among them with regard to the fractions present in larger amounts (Fig. 5). The EPMs of samples ML-1, OS-1 and BT- 1 were prominently composed of low-MW fractions (from $72.6 \mathrm{kDa}$ to 72.6-0.34 kDa), while those of samples OS-2 and BL-1 were equally represented by low-MW (from $72.6 \mathrm{kDa}$ to $72.6-0.34 \mathrm{kDa}$ ) and high-MW (larger than $2000 \mathrm{kDa}$ ) fractions. On the other hand, the EPM from sample ML-2 was prominently composed of high-MW fractions, mainly distributed in the size ranges higher than $485 \mathrm{kDa}$.

When treated as variables in PCA (Online Resource 3 and 5), the percentages of polymers with a size of $2000 \mathrm{kDa}$ and in the range $72.6-0.34 \mathrm{kDa}$ explained much of the variance in the MW distribution profile. While molecules with a size of $2000 \mathrm{kDa}$ showed high loadings on the first and second components ( 0.50 and 0.43 , respectively), polymers with a size of 72.6-0.34 $\mathrm{kDa}$ showed a high loading only on the first component $(-0.81)$.

\section{Discussion}

The analysed biocrust samples presented different morphologies and chlorophyll $a$ contents, a proxy for phototrophic abundance (Colica et al. 2015). The biocrust samples also presented different TEC contents, which is an index of biocrust development in relation to soil stability (Mazor et al. 1996; Belnap et al. 2008) and possibly an indicator of the soil C pool (Mager 2010). The samples were also characterized by different levels of development from cyanobacterial biocrusts to moss and lichen crusts. The level of development is generally associated with differences in community composition and species relative abundances ( $\mathrm{Hu}$ and Liu 2003; Liu et al. 2017). However, community succession is allowed or restricted according to semi-equilibrium with environmental stresses and the characteristics of a given location ( $\mathrm{Li}$ et al. 2013). The presence of mosses or lichens, for example, is highly conditioned by moisture, illumination 
Table 2 Monosaccharidic composition of the EPSs extracted from the six BSC samples, expressed as molar \% (i.e. moles of the specific sugar/ total moles of the sugars present in the EPSs $\times 100$ )

\begin{tabular}{llllllll}
\hline Sugar & Abbreviation & \multicolumn{7}{l}{ EPS monosaccharidic composition (molar \%) } \\
\cline { 3 - 8 } & & ML-1 & ML-2 & OS-1 & OS-2 & BL-1 & BT-1 \\
\cline { 3 - 8 } Fucose & Fuc & 4.15 & 5.22 & 9.67 & 6.96 & 4.39 & 3.78 \\
Rhamnose & Rha & 5.71 & 5.76 & 9.63 & 9.26 & 4.44 & 4.63 \\
Galactosamine & GalN & 0.40 & nd & 0.73 & 0.47 & 1.36 & 1.93 \\
Arabinose & Ara & 0.58 & 1.07 & 0.52 & 1.35 & 0.74 & 0.72 \\
Glucosamine & GlcN & 0.68 & 0.63 & 1.38 & 0.90 & 1.32 & 0.57 \\
Galactose & Gal & 5.92 & 8.56 & 9.08 & 10.00 & 7.06 & 5.48 \\
Glucose & Glc & 8.96 & 38.29 & 17.87 & 29.31 & 11.88 & 54.57 \\
Mannose & Man & 18.56 & 21.83 & 18.80 & 25.03 & 19.50 & 15.42 \\
Xylose & Xyl & 9.67 & 13.54 & 14.99 & 11.80 & 9.28 & 8.66 \\
Fructose & Fru & 0.58 & 5.09 & 0.04 & 0.69 & 1.33 & 0.66 \\
Ribose & Rib & nd & nd & 9.66 & nd & 0.69 & nd \\
Galacturonic acid & GalA & 34.02 & nd & 0.87 & 2.87 & 25.12 & 2.24 \\
Glucuronic acid & GlcA & 10.76 & nd & 6.75 & 1.37 & 12.90 & 1.33 \\
\hline
\end{tabular}

Values are means of at least three replicates, and SDs never exceeded 5\% nd Not detected and possible natural protection from wind erosion (Lan et al. 2014). Consequently, some cyanobacterial crusts may be prevented from shifting to moss or lichen crusts, implying that LOD does not necessarily coincide with crust age.

Samples BL-1 (moss crust), BT-1 (semi-moss crust) and OS-2 (cyanobacterial crust with scarce moss colonization) showed the highest chlorophyll contents. Chlorophyll $a$ content reflected the differences in moss colonization between the three samples, in the order BL-1>BT-1> OS-2. Moss crusts are considered the latest and most mature stage of biocrust LOD, characterized by an increased biomass content (Liu et al. 2013), increased nitrogenase activity, and higher EPS productivity compared to those of cyanobacterial biocrusts (Liu et al. 2017). Additionally, moss crusts are characterized by a higher presence of biomass-degrading microorganisms than early-LOD biocrusts, improving their nutrient status (Maier et al. 2018). Accordingly, in these samples, we detected the largest mean relative amounts of TECs and HMWECs. An exception was sample ML-1 (classifiable as a lichen crust), which, although displaying one of the lowest chlorophyll contents, showed a high TEC content, although not a high HMWEC content. In this case, a high TEC content might support improved $\mathrm{C}$ fixation rates, a common feature of lichen crusts (Liu et al. 2017).

Our set of samples differed in HMWEC content. This EPS fraction (MW $\geq 100 \mathrm{kDa}$ ) is the direct product of microbial synthesis and strongly contributes to biocrust EPM stability (Mugnai et al. 2018a). Several microbial groups synthesize HMWECs, notably cyanobacteria, which are known for producing high-MW polymers (Pereira et al. 2009). Sample OS-2, a cyanobacterial crust also analysed in another study (Felde et al. 2016), was characterized by the dominance of Gloeocapsa sp., a genus known for producing a large, thick
EPS envelope. We did not find any statistical correlation between chlorophyll content and HMWEC content. Conversely, a strong positive correlation between chlorophyll and HMWEC contents was found for biocrusts from hot arid environments, thus suggesting that cyanobacteria contribute to their synthesis (Rossi et al. 2012b). However, the lack of correlation may depend on the more rapid community changes characterizing Arctic biocrusts compared to hot dryland biocrusts. According to Schostag et al. (2015), our study sites are characterized by seasonal variation in phototrophic abundance, owing to the decline in the relative abundance of chloroplasts and cyanobacteria starting from mid-summer, with the lowest relative abundances registered in late summer and autumn. Therefore, chlorophyll content may depend on the time of sampling (late August), in which cyanobacterial abundance is the lowest. Nevertheless, since cyanobacterial sheaths and more condensed EPSs remain to cement soil particles even after death or migration of the producing strain (Zhang 2005; Rossi et al. 2018), the secretion events may have preceded the sampling period.

IEC analysis showed that the polysaccharidic fraction of the EPM contained dominant relative percentages of hexoses (glucose and mannose) and, in the case of samples ML-1 and BL-1, uronic acids. In addition, the deoxy sugars fucose and rhamnose were detected in all the samples, in percentages from 4 to $9 \%$. Except for some differences (see below), the EPMs of the samples showed similar monosaccharidic compositions. Such a composition is superimposable to that typical of cyanobacterial EPSs in regard to the number and quality of the constituents (De Philippis and Vincenzini 1998). Additionally, it is of a comparable complexity to that of cyanobacteria-dominated biocrusts from Chinese hot arid soils (Wang et al. 2009; Colica et al. 2015). The presence 


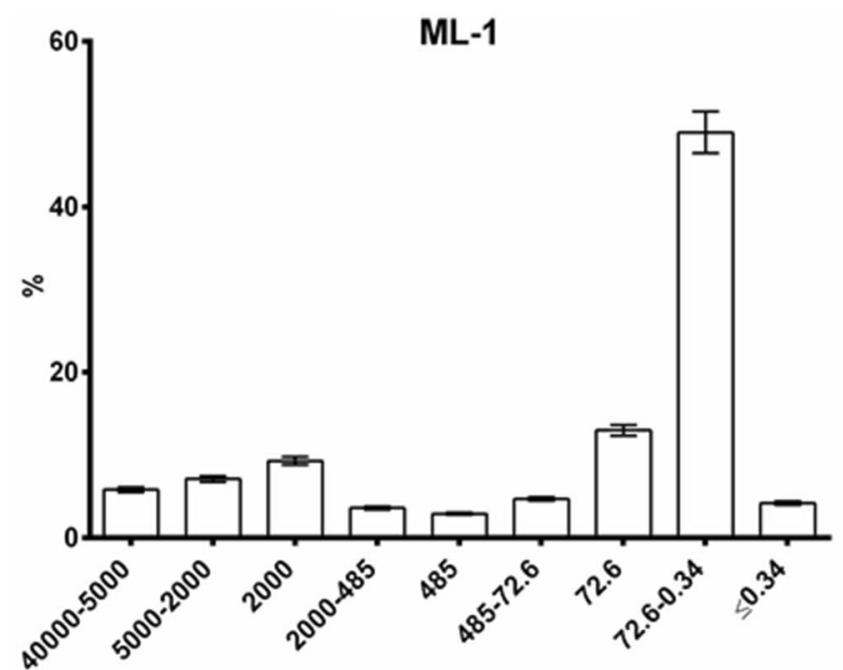

OS-1

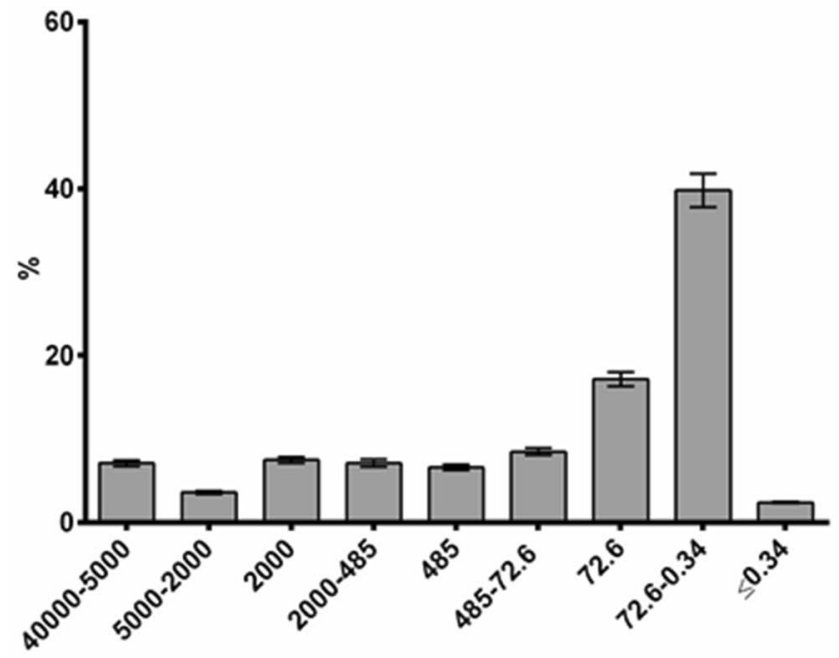

BL-1

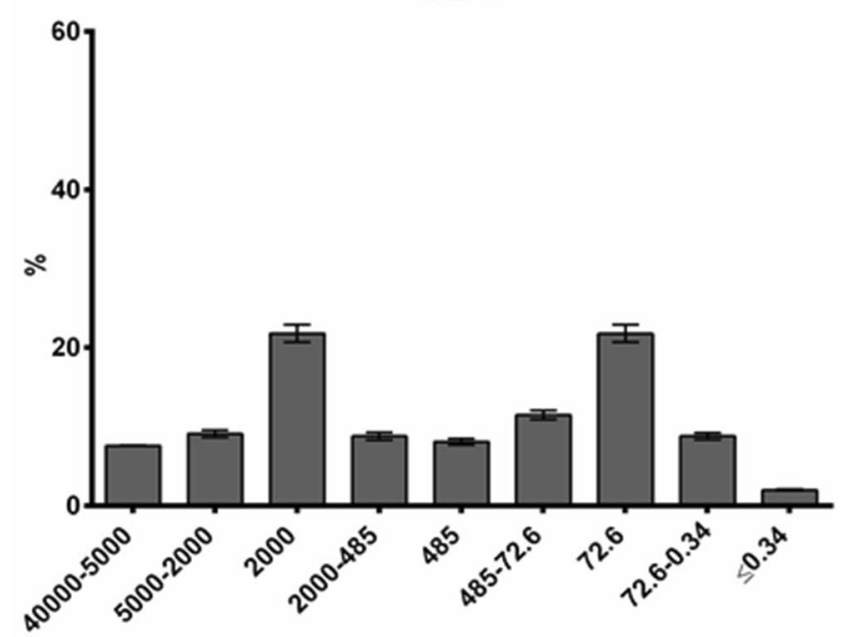

MW distribution (kDa)
ML-2

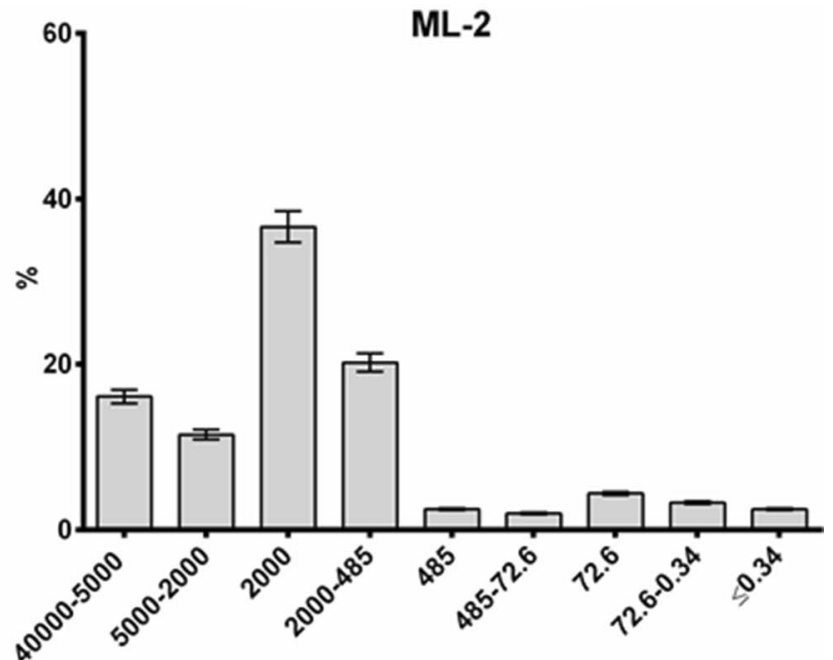

OS-2

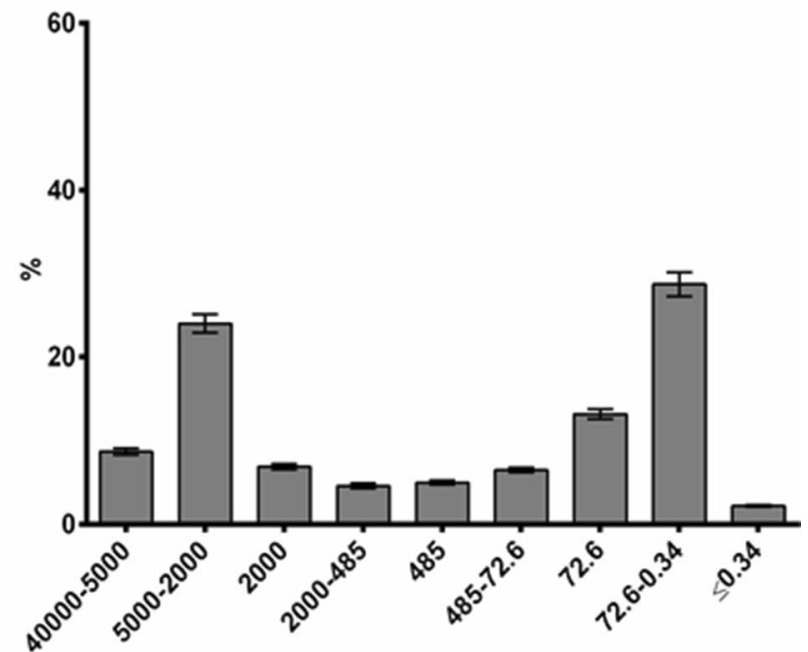

BT-1

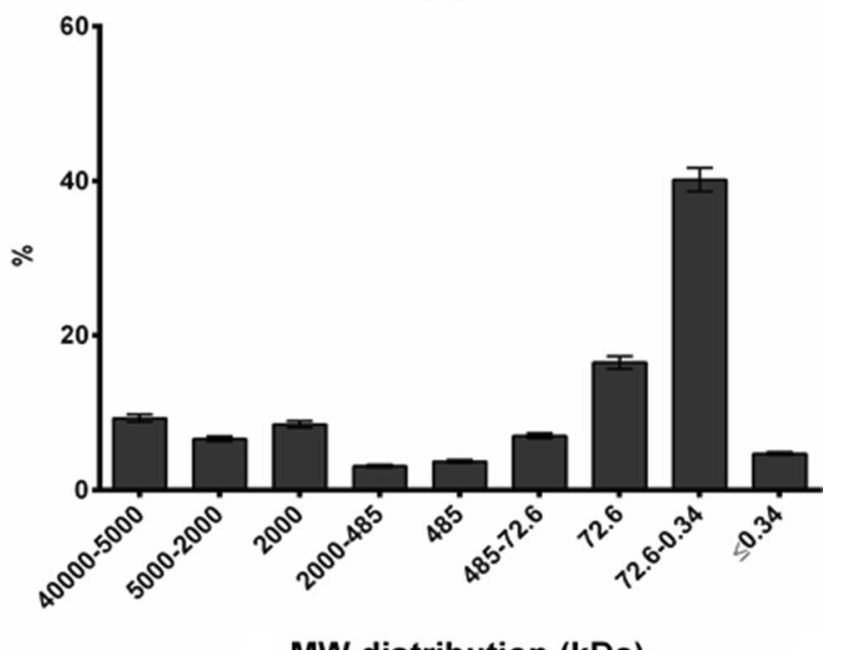

MW distribution (kDa) 
4Fig. 5 MW distribution of the EPS fractions. MW classes were assigned according to dextran standards at known average MWs, namely, 40-5 MDa, and 2000, 485, 72.6 and $0.34 \mathrm{kDa}$. Nine size classes were identified: $40,000-5000 \mathrm{kDa} ; 5000-2000 \mathrm{kDa}$; $2000 \mathrm{kDa} ; 2000-485 \mathrm{kDa} ; 485 \mathrm{kDa} ; 485-72.6 \mathrm{kDa} ; 72.6 \mathrm{kDa} ; 72.6-$ $0.34 \mathrm{kDa}$; and $\leq 0.34 \mathrm{kDa}$. Results are the means of three different replicates $(N=3)$, and SDs never exceeded 5\%

of uronic acids on one side and rhamnose and fucose on the other confers both a hydrophobic and a hydrophilic character to the EPM, depending on the relative abundances, contributing to the establishment of different types of interactions with the surrounding environment (Pereira et al. 2009; Rossi et al. 2012a). Principal component analysis performed on monosaccharide composition showed that variance in the data was explained by the relative contents of glucose and galacturonic acid (Online Resource 2 and 4). Owing to their hydrophilia, uronic acids confer a water-absorptive character to the EPM, maintaining optimal moist conditions for the biocrust community (Pereira et al. 2009). We previously observed that an increase in the relative abundance of uronic acids was associated with biocrust age (Colica et al. 2015). Our current results evidenced a higher uronic acid contents in samples BL-1 and ML-1, which were a moss crust and a lichen crust, respectively, types of biocrusts considered to be of a later stage of development (Belnap et al. 2008). Galacturonic acid was particularly abundant in the EPM of sample ML-1. Conversely, sample ML-2 did not contain uronic acids. The lack of uronic acids is indicative of an incipient biocrust stage (Colica et al. 2015), also supported by the lower levels of chlorophyll and EPSs.

Contrary to the IEC results, SEC revealed a MW distribution differing from that of biocrusts sampled from other climatic zones. A common trait observed among samples from Inner Mongolian Desert biocrusts is the significant presence of fractions with apparent MWs in the range $2000-485 \mathrm{kDa}$ (Chen et al. 2014; Colica et al. 2015). We did not observe common traits in the MW distribution profiles of the EPMs of the present samples. According to PCA, the variance in the data was explained by the relative abundances of polymers with an apparent MW of $2000 \mathrm{kDa}$ and those with an apparent MW between 72.6 and 0.34 kDa (Online Resource 3 and 5). The variation in the abundance of polymers belonging to these two size classes is indicative of different microbial activities between the samples, causing variations in EPM synthetic and degradative patterns (Chen et al. 2014). The differences from biocrusts from hot deserts can probably be explained by the more variegated and variable environmental conditions characterizing Arctic tundra. Our samples showed three different MW distribution patterns. In the first, characterizing samples ML-1, OS-1 and BT-1, the EPM contained polymers with MWs primarily between 72.6 and $0.34 \mathrm{kDa}$, corresponding to small polymers or oligomers. This indicates prevalent polymer-degrading activity and an accumulation of small compounds (Chen et al. 2014). The second MW distribution pattern belonged to samples OS-2 and BL-1, in which the EPM was characterized by both high- $(\geq 2000 \mathrm{kDa})$ and low-MW polymers (in the range $72.6-0.34 \mathrm{kDa}$ ). In this case, the polymer-degrading activity is coupled with the synthetic activity of high-MW EPSs by cyanobacteria and other producing species. In a third MW distribution pattern, characterizing sample ML-2, the EPM constituted only high-MW polymers, distributed in several size classes from $450 \mathrm{kDa}$ upwards. This is indicative of the low enzymatic activity and prevailing synthetic activity of high-MW polymers. Our results showed that the largest relative contents of low-MW polymers prevailed in the EPMs of mature samples, notably sample ML-1 (50\%), a lichen crust; sample OS-1 (41\%), a black crust sparsely colonized by lichens; and sample BT-1 (41\%), a semi-moss crust also sparsely colonized by lichens. The biocrust level of development is strongly related to microbial enzymatic activity. Miralles et al. (2012) and Liu et al. (2014) demonstrated that cyanobacterial crusts are characterized by the lowest activity of hydrolytic enzymes, which is also positively related to the presence of mosses and lichens. The MW distribution patterns of our samples seem to confirm this assumption. Indeed, sample ML-2, for which we detected an EPM composed of only polymers distributed in the high-MW classes, could be classified as an early-stage biocrust according to sample morphology, lower levels of TECs and HMWECs, and a lack of uronic acids as EPM components.

In conclusion, this study reports for the first time the characteristics of the EPMs of High Arctic biocrusts, specifically providing information on their monosaccharide composition and MW distribution profiles. We underlined several divergent traits compared to those of biocrusts developed in temperate environments. The major detected difference between the samples concerns the MW distribution profiles of the EPM, which are the result of the synthetic but also the hydrolytic activity of the microbial communities. Most likely, the more variable environmental conditions at the micro and macro scales compared to those of hot drylands caused biocrusts differing in community structure and composition, which in turn influenced species interactions and hence EPM characteristics. We found that the significant presence of low-MW EPM fractions, possibly an index of hydrolytic enzyme activity, was enhanced in mature biocrusts colonized by mosses or lichens. In later-stage biocrusts, the EPM was also characterized by the marked presence of uronic acids, which are important for all the hydrophilic interactions of the EPSs with the surrounding environment and contribute to ensuring a lower-abioticstress microenvironment by maintaining a high level of water in the soil. Furthermore, this work also confirms the possibility, already hinted at in previous studies on biocrusts from hot biomes, of using some parameters to gauge biocrust 
age and maturation. In particular, the relative content of uronic acid in the EPSs and the presence of low-MW EPS fractions, whose content is positively related to enzymatic activity, could be used as possible indices. However, further studies involving samples from more climatic areas are necessary to extrapolate definitive sound correlations.

Acknowledgements This study received funding from the Italian Ministry of University and Research (MIUR) in the framework of the Piano Nazionale di Ricerca sull'Antartide (PNRA 2014-2016), Project "Biological Soil Crusts; microbial biodiversity; metagenomics; metabolomics; microstructure" (WHYCRUST).

Funding Open access funding provided by Università degli Studi di Firenze within the CRUI-CARE Agreement.

\section{Compliance with ethical standards}

Conflict of interest The authors declare that they have no known competing financial interests or personal relationships that could have appeared to influence the work reported in this paper.

Open Access This article is licensed under a Creative Commons Attribution 4.0 International License, which permits use, sharing, adaptation, distribution and reproduction in any medium or format, as long as you give appropriate credit to the original author(s) and the source, provide a link to the Creative Commons licence, and indicate if changes were made. The images or other third party material in this article are included in the article's Creative Commons licence, unless indicated otherwise in a credit line to the material. If material is not included in the article's Creative Commons licence and your intended use is not permitted by statutory regulation or exceeds the permitted use, you will need to obtain permission directly from the copyright holder. To view a copy of this licence, visit http://creativecommons.org/licenses/by/4.0/.

\section{References}

Al-Thani RF (2015) Cyanomatrix and cyanofilm. J Res Dev 3(1):1-4. https://doi.org/10.4172/2311-3278.1000123

Belnap J, Lange OL (2001) Biological soil crusts: structure, function, and management. Springer, New York

Belnap J, Phillips SL, Witwicki DL, Miller ME (2008) Visually assessing the level of development and soil surface stability of cyanobacterially dominated biological soil crusts. J Arid Environ 72(7):1257-1264. https://doi.org/10.1016/j.jaridenv.2008.02.019

Breen K, Lévesque E (2008) The influence of biological soil crusts on soil characteristics along a High Arctic Glacier Foreland, Nunavut, Canada. Arct Antarct Alp Res 40:287-297. https://doi. org/10.1657/1523-0430(06-098)[BREEN]2.0.CO;2

Brouwer JFC, Stal LJ (2001) Short-term dynamics in microphytobenthos distribution and associated extracellular carbohydrates in surface sediments of an intertidal mudflat. Mar Ecol Prog Ser 218:33-44. https://doi.org/10.3354/meps218033

Castle SC, Morrison CD, Barger NN (2011) Extraction of chlorophyll a from biological soil crusts: a comparison of solvents for spectrophotometric determination. Soil Biol Biochem 43:853-856. https ://doi.org/10.1016/j.soilbio.2010.11.025

Chamizo S, Mugnai G, Rossi F et al (2018) Cyanobacteria inoculation improves soil stability and fertility on different textured soils: gaining insights for applicability in soil restoration. Front Environ Sci 6:1-14. https://doi.org/10.3389/fenvs.2018.00049

Chen L, Rossi F, Deng S et al (2014) Macromolecular and chemical features of the excreted extracellular polysaccharides in induced biological soil crusts of different ages. Soil Biol Biochem 78:1-9. https://doi.org/10.1016/j.soilbio.2014.07.004

Chock T, Antoninka AJ, Faist AM et al (2019) Responses of biological soil crusts to rehabilitation strategies. J Arid Environ 163:77-85. https://doi.org/10.1016/j.jaridenv.2018.10.007

Colica G, Li H, Rossi F et al (2014) Microbial secreted exopolysaccharides affect the hydrological behavior of induced biological soil crusts in desert sandy soils. Soil Biol Biochem 68:62-70. https:// doi.org/10.1016/j.soilbio.2013.09.017

Colica G, Li H, Rossi F et al (2015) Differentiation of the characteristics of excreted extracellular polysaccharides reveals the heterogeneous primary succession of induced biological soil crusts. J Appl Phycol 27:1935-1944. https://doi.org/10.1007/s1081 1-015-0532-6

De Philippis R, Vincenzini M (1998) Exocellular polysaccharides from cyanobacteria and their possible applications. FEMS Microbiol Rev 22:151-175. https://doi. org/10.1111/j.1574-6976.1998.tb00365.x

Dubois M, Gilles KA, Hamilton JK et al (1956) Colorimetric method for determination of sugars and related substances. Anal Chem 28:350-356. https://doi.org/10.1021/ac60111a017

Felde VJMNL, Rossi F, Colesie C et al (2016) Pore characteristics in biological soil crusts are independent of extracellular polymeric substances. Soil Biol Biochem 103:294-299. https://doi. org/10.1016/j.soilbio.2016.08.029

Fierer N, Schimel JP, Holden PA (2003) Variations in microbial community composition through two soil depth profiles. Soil Biol Biochem 35:167-176. https://doi.org/10.1016/S0038 $-0717(02) 00251-1$

Hu C-X, Liu Y-D (2003) Primary succession of algal community structure in desert soil. Acta Bot Sin 45(8): 917-924. https:// hdl.handle.net/1807/1945

Jung P, Briegel-Williams L, Simon A et al (2018) Uncovering biological soil crusts: carbon content and structure of intact Arctic, Antarctic and alpine biological soil crusts. Biogeosciences 15:1149-1160. https://doi.org/10.5194/bg-15-1149-2018

Krzyszowska AJ (1989) Human impact on tundra environment at the Ny-Ålesund Station. Svalbard Polar Res 7(2):119-131. https:// doi.org/10.3402/polar.v7i26836

Lan S, Wu L, Zhang D, Hu C (2013) Assessing level of development and successional stages in biological soil crusts with biological indicators. Microb Ecol 66:394-403. https://doi.org/10.1007/ s00248-013-0191-6

Lan S, Zhang Q, Wu L et al (2014) Artificially accelerating the reversal of desertification: cyanobacterial inoculation facilitates the succession of vegetation communities. Environ Sci Technol 48:307-315. https://doi.org/10.1021/es403785j

Li H, Colica G, Wu P et al (2013) Shifting species interaction in soil microbial community and its influence on ecosystem functions modulating. Microb Ecol 65:700-708. https://doi.org/10.1007/ s00248-012-0171-2

Liu Y, Li X, Xing Z, Zhao X, Pan Y (2013) Responses of soil microbial biomass and community composition to biological soil crusts in the revegetated areas of the Tengger Desert. Appl Soil Ecol 65:52-59. https://doi.org/10.1016/j.apsoil.2013.01.005

Liu L, Liu Y, Zhang P et al (2017) Development of bacterial communities in biological soil crusts along a revegetation chronosequence in the Tengger Desert, northwest China. Biogeosciences 14:3801-3814. https://doi.org/10.5194/bg-14-3801-2017

Liu Y, Yang H, Li X, Xing Z (2014) Effects of biological soil crusts on soil enzyme activities in revegetated areas of the 
Tengger Desert, China. Appl Soil Ecol 80:6-14. https://doi. org/10.1016/j.apsoil.2014.03.015

Mager D (2010) Carbohydrates in cyanobacterial soil crusts as a source of carbon in the southwest Kalahari. Botswana Soil Biol Biochem 42(2):313-318. https://doi.org/10.1016/j.soilb io.2009.11.009

Mager DM, Thomas AD (2011) Extracellular polysaccharides from cyanobacterial soil crusts: a review of their role in dryland soil processes. J Arid Environ 75:91-97. https://doi.org/10.1016/j.jarid env.2010.10.001

Maier S, Tamm A, Wu D, Caesar J, Grube M, Weber B (2018) Photoautotrophic organisms control microbial abundance, diversity, and physiology in different types of biological soil crusts. ISME J 12(4):1032-1046. https://doi.org/10.1038/s41396-018-0062-8

Mann DH, Sletten RS, Ugolini FC (1986) Soil development at Kongsfjorden, Spitsbergen. Polar Res 4:1-16. https://doi.org/10.3402/ polar.v4i1.6914

Mazor G, Kidron GJ, Vonshak A, Abeliovich A (1996) The role of cyanobacterial exopolysaccharides in structuring desert microbial crusts. FEMS Microbiol Ecol 21:121-130. https://doi. org/10.1111/j.1574-6941.1996.tb00339.x

Miralles I, Domingo F, Cantón Y et al (2012) Hydrolase enzyme activities in a successional gradient of biological soil crusts in arid and semi-arid zones. Soil Biol Biochem 53:124-132. https://doi. org/10.1016/j.soilbio.2012.05.016

Mugnai G, Rossi F, Felde VJMNL et al (2018a) Development of the polysaccharidic matrix in biocrusts induced by a cyanobacterium inoculated in sand microcosms. Biol Fertil Soils 54:27-40. https ://doi.org/10.1007/s00374-017-1234-9

Mugnai G, Rossi F, Martin Noah Linus Felde VJ et al (2018b) The potential of the cyanobacterium Leptolyngbya ohadii as inoculum for stabilizing bare sandy substrates. Soil Biol Biochem 127:318328. https://doi.org/10.1016/j.soilbio.2018.08.007

Mugnai G, Rossi F, Chamizo S et al (2020) The role of grain size and inoculum amount on biocrust formation by Leptolyngbya ohadii. CATENA 184:104248. https://doi.org/10.1016/j.caten a.2019.104248

Pereira S, Zille A, Micheletti E et al (2009) Complexity of cyanobacterial exopolysaccharides: composition, structures, inducing factors and putative genes involved in their biosynthesis and assembly. FEMS Microbiol Rev 33:917-941. https://doi.org/10 .1111/j.1574-6976.2009.00183.x

Pushkareva E, Pessi IS, Wilmotte A, Elster J (2015) Cyanobacterial community composition in Arctic soilcrusts at different stages of development. FEMS Microbiol Ecol 91:1-10. https://doi. org/10.1093/femsec/fiv143

Pushkareva E, Wilmotte A, Láska K, Elster J (2019) Comparison of microphototrophic communities living in different soil environments in the High Arctic. Front Ecol Evol. https://doi.org/10.3389/ fevo.2019.00393

Rossi F, Micheletti E, Bruno L et al (2012a) Characteristics and role of the exocellular polysaccharides produced by five cyanobacteria isolated from phototrophic biofilms growing on stone monuments. Biofouling 28:215-224. https://doi.org/10.1080/08927 014.2012.663751

Rossi F, Mugnai G, De Philippis R (2018) Complex role of the polymeric matrix in biological soil crusts. Plant Soil 429:19-34. https ://doi.org/10.1007/s11104-017-3441-4

Rossi F, Potrafka RM, Pichel FG, De Philippis R (2012b) The role of the exopolysaccharides in enhancing hydraulic conductivity of biological soil crusts. Soil Biol Biochem 46:33-40. https://doi. org/10.1016/j.soilbio.2011.10.016

Schostag M, Stibal M, Jacobsen CS et al (2015) Distinct summer and winter bacterial communities in the active layer of Svalbard permafrost revealed by DNA- and RNA-based analyses. Front Microbiol 6:1-14. https://doi.org/10.3389/fmicb.2015.00399

Tamaru Y, Takani Y, Yoshida T, Sakamoto T (2005) Crucial role of extracellular polysaccharides in desiccation and freezing tolerance in the terrestrial cyanobacterium nostoc commune. Appl Environ Microbiol 71:7327-7333. https://doi.org/10.1128/ AEM.71.11.7327-7333.2005

Underwood GJC, Paterson DM, Parkes RJ (1995) The measurement of microbial carbohydrate exopolymers from intertidal sediments. Limnol Oceanogr 40:1243-1253. https://doi.org/10.4319/ lo.1995.40.7.1243

Varin T, Lovejoy C, Jungblut AD et al (2012) Metagenomic analysis of stress genes in microbial mat communities from Antarctica and the High Arctic. Appl Environ Microbiol 78:549-559. https://doi. org/10.1128/AEM.06354-11

Wang W, Liu Y, Li D et al (2009) Feasibility of cyanobacterial inoculation for biological soil crusts formation in desert area. Soil Biol Biochem 41:926-929. https://doi.org/10.1016/j.soilb io.2008.07.001

Wild B, Schnecker J, Alves RJE et al (2014) Input of easily available organic $\mathrm{C}$ and $\mathrm{N}$ stimulates microbial decomposition of soil organic matter in arctic permafrost soil. Soil Biol Biochem 75:143-151. https://doi.org/10.1016/j.soilbio.2014.04.014

Williams L, Borchhardt N, Colesie C et al (2017) Biological soil crusts of Arctic Svalbard and of Livingston Island, Antarctica. Polar Biol 40:399-411. https://doi.org/10.1007/s00300-016-1967-1

Yoshitake S, Uchida M, Koizumi H et al (2010) Production of biological soil crusts in the early stage of primary succession on a High Arctic glacier foreland. New Phytol 186:451-460. https://doi.org /10.1111/j.1469-8137.2010.03180.x

Zhang Y (2005) The microstructure and formation of biological soil crusts in their early developmental stage. Chin Sci Bull 50:117121. https://doi.org/10.1007/BF02897513

Publisher's Note Springer Nature remains neutral with regard to jurisdictional claims in published maps and institutional affiliations. 